\title{
Combined effects of a dietary portfolio of plant sterols, vegetable protein, viscous fibre and almonds on LDL particle size
}

\author{
Benoît Lamarche $^{1 *}$, Sophie Desroches ${ }^{1}$, David J. A. Jenkins ${ }^{2,3,4,5}$, Cyril W. C. Kendall ${ }^{2,4}$, \\ Augustine Marchie ${ }^{2,4}$, Dorothea Faulkner ${ }^{2,4}$, Edward Vidgen ${ }^{2,4}$, Karen G. Lapsley ${ }^{8}$, Elke A. Trautwein ${ }^{9}$, \\ Tina L. Parker ${ }^{2,4}$, Robert G. Josse ${ }^{2,3,4,5}$, Lawrence A. Leiter ${ }^{2,3,4,5}$ and Philip W. Connelly, $3,6,7$ \\ ${ }^{1}$ Institute on Nutraceuticals and Functional Foods, Laval University, Ste-Foy, Québec, Canada \\ ${ }^{2}$ Clinical Nutrition and Risk Factor Modification Center and \\ ${ }^{3}$ Department of Medicine, Division of Endocrinology and Metabolism, St Michael's Hospital, Toronto, Ontario, Canada \\ Departments of ${ }^{4}$ Nutritional Sciences, ${ }^{5}$ Medicine, ${ }^{6}$ Biochemistry and ${ }^{7}$ Laboratory Medicine and Pathobiology, Faculty of \\ Medicine, University of Toronto, Toronto, Ontario, Canada \\ ${ }^{8}$ The Almond Board of California, Modesto, California, USA \\ ${ }^{9}$ Unilever Health Institute, Unilever R\&D Vlaardingen, The Netherlands
}

(Received 19 January 2004 - Revised 9 June 2004 - Accepted 17 June 2004)

\begin{abstract}
Studies conducted in the last 20 years have led to the identification of small dense LDL as an important risk factor for CVD. Consumption of plant sterols, soyabean proteins, viscous fibre and nuts are known to modulate the risk of CVD favourably through their cholesterol (Chol)-lowering properties, both independently and more recently in combination. Nevertheless, their combined impact on the LDL particle size phenotype has never been tested. In the present study, we assessed the effect of incorporating concurrently plant sterols $(1 \mathrm{~g} / 4 \cdot 2 \mathrm{MJ})$, soyabean protein $(23 \mathrm{~g} / 4 \cdot 2 \mathrm{MJ})$, viscous fibre $(9 \mathrm{~g} / 4 \cdot 2 \mathrm{MJ})$ and almonds $(15 \mathrm{~g} / 4 \cdot 2 \mathrm{MJ})$ into a diet very low in saturated fat in twelve patients with mildly elevated plasma LDL-Chol levels. Fasting blood lipids were obtained at the start of the study and at 2-week intervals during the 4-week study. The diet-induced reduction in plasma LDL-Chol of 30.0 (SE 3.0) \% $(P<0 \cdot 0001)$ was attributed to concurrent reductions in the serum Chol concentrations of large ( $>26.0 \mathrm{~nm}-30$ (SE 8) \%, $P<0 \cdot 001)$, medium $(25.5-26.0 \mathrm{~nm}-29$ (SE 3) $\%, P<0 \cdot 001)$ and small $(<25.5 \mathrm{~nm}-21$ (SD 6) \%, $P<0.01)$ LDL particles, with near maximal reductions seen by week 2 . These results indicate that foods and dietary components advocated for their potential to reduce the risk of CVD are effective in reducing serum concentrations of all LDL fractions including small dense LDL, thus potentially further contributing to an overall lower risk of CVD.
\end{abstract}

LDL particle size: Plant sterols: Soyabean protein: Viscous dietary fibre: Almonds

Small dense LDL particles have been associated with an increased risk of CVD (Gardner et al. 1996; Lamarche et al. 1997, 1999). Whether measurement of LDL particle size or phenotype provides additional or complementary information on CVD risk, independent of more traditional lipid risk factors such as plasma LDL-cholesterol (Chol) or triacylglycerol (TG) levels, remains a matter of debate (Lamarche et al. 1999). Recent results from the Québec Cardiovascular Study have provided new insights into the relationship between small dense LDL and the risk of CVD (St Pierre et al. 2001). First, LDL peak particle diameter, which has been used widely as a surrogate for small dense LDL particles in most previous epidemiological studies, appeared as a weak multivariate predictor of CVD risk. However, other electrophoretic characteristics of LDL particles, such as the proportion of small LDL particles (LDL \%<25.5 nm) and the Chol concentration of LDL particles $<25.5 \mathrm{~nm}\left(\mathrm{LDL}-\mathrm{Chol}_{<25.5 \mathrm{~nm}}\right)$, were identified as very powerful and independent risk predictors in middle-aged men, even after adjustment for other variables of the CVD risk profile, including the more traditional measure of the LDL-peak particle diameter (PPD; St Pierre et al. 2001).

Recent studies from our group (Jenkins et al. 2002, 2003) have demonstrated the potent Chol-lowering properties of a combination (portfolio) diet simultaneously incorporating viscous fibre, plant sterols, vegetable protein (soyabean) and nuts (almonds), four dietary components that have been accepted for health claims by the Food and Drug Administration in the USA (US Department of Agriculture, 2003). There is currently only limited data on the individual effect that these dietary components may have on the LDL particle size phenotype (MerzDemlow et al. 2000; Almario et al. 2001; Wangen et al. 
2001; Matvienko et al. 2002; Charest et al. 2004; Desroches et al. 2004). In addition, there are currently no data on the impact on LDL particle size resulting from the very large reductions in LDL-Chol attributable to the consumption of a range of Chol-lowering components used in combination. The purpose of the present study was therefore to assess the changes in the electrophoretic characteristics of LDL particles in response to a diet very low in saturated fat and incorporating simultaneously viscous fibre, soyabean protein, plant sterols and almonds in hyperlipidaemic subjects.

\section{Materials and methods}

\section{Subjects}

Data on the impact of the combination diet on LDL-Chol and on several cardiovascular risk factors have been reported earlier (Jenkins et al. 2002, 2003). For the present analysis, LDL particle size phenotype was obtained in twelve of the thirteen original subjects (six men and six postmenopausal women), aged 65 (SE 3) (range 43-84) years with a mean BMI 25.8 (SE 3.4) (range 20.6-30.7) $\mathrm{kg} / \mathrm{m}^{2}$. Their mean baseline LDL-Chol level was $4 \cdot 20$ (SE 0.12 ) (range 3.51-4.99) mmol/l. Briefly, participants were recruited from patients attending the Risk Factor Modification Center, St Michael's Hospital, Toronto, Ont., Canada. All subjects had taken part in previous dietary studies and were experienced in following dietary protocols. The main inclusion criteria were to previously have had raised LDL-Chol levels $(>4.1 \mathrm{mmol} / \mathrm{l})$, to have a BMI $<38 \mathrm{~kg} / \mathrm{m}^{2}$ and to live within $16 \mathrm{~km}$ of St Michael's Hospital for practical purposes. At the time of the study, five subjects had raised LDL-Chol levels, one subject had raised TG levels $(>2.30 \mathrm{mmol} / \mathrm{l})$, three subjects had both raised Chol and TG levels, one subject had low HDLChol levels $(<0.9 \mathrm{mmol} / \mathrm{l})$ and three subjects had blood lipids in the normal range. No subjects had a history of diabetes, renal or liver disease and none were taking medications known to influence serum lipids.

\section{Study protocol}

Subjects were monitored on their own usual low-saturated fat therapeutic diets for 1 week preceding the 4-week intervention with the combination diet, for which most foods were provided to participants (Jenkins et al. 2002). This allowed us to document the nature of the diet that participants had been following in the preceding months and that would be reflected in the blood sample obtained at the end of that 'run-in' week. A 2-week washout period, during which participants returned to their low-saturated fat therapeutic diets, followed the combination diet. Blood samples and body weights were obtained after $12 \mathrm{~h}$ overnight fasts at 1-week intervals and at week 2 of the washout period. Weighed diet histories $(7 \mathrm{~d})$, during which subjects weighed all the food they consumed, were obtained for $7 \mathrm{~d}$ prior to and 2 weeks following the combination diet, as described previously (Jenkins et al. 2002). During the 4 weeks on the combination diet, completed menu checklists were returned at weekly intervals.

The study was approved by the Ethics Committee of the University of Toronto and St Michael's Hospital and informed consent was obtained from all the subjects.

\section{Diets}

The diets eaten before and after the 4-week combination diet were the subjects' routine therapeutic low-fat diets, which followed the National Cholesterol Education Program Step 2 guidelines ( $\leq 7 \%$ energy from saturated fat and $<200 \mathrm{mg}$ dietary Chol/d) (Table 1) (National Cholesterol Education Program, 2002). Subjects were provided with self-tareing electronic scales and asked to weigh all food items consumed during the study period. During the combination diet period, all foods to be consumed by the subjects were provided at weekly clinic visits with the exception of fruits and low-energy vegetables, i.e. nonstarch-containing vegetables, which subjects were instructed to obtain from their local stores as previously described (Jenkins et al. 2002, 2003). A 4-week intervention period was judged adequate based on previous work from our

Table 1. Calculated macronutrient intakes during the baseline, test and run-out periods of the combination diet $^{*}$

\begin{tabular}{|c|c|c|c|c|c|c|}
\hline & \multicolumn{2}{|c|}{ Baseline (week 0) } & \multicolumn{2}{|c|}{$\begin{array}{l}\text { Test (mean of } \\
\text { weeks } 2-4 \text { ) }\end{array}$} & \multicolumn{2}{|c|}{ Run-out (week 6) } \\
\hline & Mean & SD & Mean & SD & Mean & SD \\
\hline Energy $(\mathrm{MJ} / \mathrm{d})$ & $7 \cdot 13^{a}$ & $1 \cdot 73$ & $8 \cdot 36^{\mathrm{b}}$ & $1 \cdot 8$ & $7 \cdot 13^{a}$ & 1.52 \\
\hline Total protein (\% energy) & $17 \cdot 3^{\mathrm{a}}$ & $2 \cdot 8$ & $22 \cdot 4^{\mathrm{b}}$ & 1.8 & $18 \cdot 1^{\mathrm{a}}$ & $2 \cdot 8$ \\
\hline Vegetable protein (\% protein) & $48 \cdot 7^{\mathrm{b}}$ & $12 \cdot 1$ & $96 \cdot 8^{\mathrm{C}}$ & 0.7 & $39 \cdot 1^{\mathrm{a}}$ & $9 \cdot 7$ \\
\hline Available carbohydrate (\% energy) & $52.9^{\mathrm{ab}}$ & $9 \cdot 7$ & $50 \cdot 6^{\mathrm{a}}$ & $2 \cdot 2$ & $58 \cdot 2^{\mathrm{b}}$ & 4.5 \\
\hline Total dietary fibre $(\mathrm{g} / 4.2 \mathrm{MJ})$ & $17 \cdot 1^{\mathrm{a}}$ & $6 \cdot 6$ & $30 \cdot 7^{b}$ & $2 \cdot 9$ & $17 \cdot 8^{\mathrm{a}}$ & $6 \cdot 2$ \\
\hline Total fat (\% energy) & $28 \cdot 3$ & $8 \cdot 7$ & $27 \cdot 0$ & $2 \cdot 9$ & $22 \cdot 7$ & $5 \cdot 2$ \\
\hline SFA (\% energy) & $7 \cdot 7^{\mathrm{b}}$ & $2 \cdot 4$ & $4 \cdot 3^{\mathrm{a}}$ & 0.4 & $6 \cdot 2^{\mathrm{ab}}$ & 2.4 \\
\hline MUFA (\% energy) & 11.9 & 5.5 & 11.8 & $1 \cdot 8$ & $9 \cdot 0$ & $2 \cdot 4$ \\
\hline PUFA (\% energy) & $6 \cdot 0^{\mathrm{a}}$ & 1.4 & $9.9^{\mathrm{b}}$ & 0.7 & $5 \cdot 3^{\mathrm{a}}$ & 1.7 \\
\hline Dietary cholesterol (mg/4.2 MJ) & $99^{\mathrm{b}}$ & 45 & $10^{\mathrm{a}}$ & 11 & $79^{\mathrm{b}}$ & 31 \\
\hline Alcohol (\% energy) & $1.5^{\mathrm{a}}$ & 1.7 & $0.2^{\mathrm{b}}$ & 0.4 & $1 \cdot 0^{\mathrm{a}}$ & 1.0 \\
\hline
\end{tabular}

SFA, saturated fatty acids.

a,b Mean values within a row with unlike superscript letters were significantly different $(P<0.05)$

${ }^{\star}$ For details of subjects and procedures, see pp. 658-659. 
group, which has shown that near maximum falls in serum Chol occurred within the first week of the dietary regimen (Wolever et al. 1997; Jenkins et al. 2001).

The aim of the combination diet was to provide: $1 \mathrm{~g}$ plant sterols $/ 4.2 \mathrm{MJ}$ as an enriched margarine, $8.2 \mathrm{~g}$ viscous fibre/ 4.2 MJ from oats, barley and psyllium, and $22.7 \mathrm{~g}$ soyabean protein/4.2 MJ. Raw unblanched almonds also provided vegetable protein $(2.9 \mathrm{~g} / 4.2 \mathrm{MJ})$. Emphasis was placed on aubergine and okra as additional sources of viscous fibre ( $0.55 \mathrm{~g} / 4.2 \mathrm{MJ}$ and $0.67 \mathrm{~g} / 4.2 \mathrm{MJ}$ respectively). Thus, $200 \mathrm{~g}$ aubergine and $100 \mathrm{~g} \mathrm{okra} / \mathrm{d}$ were prescribed to be eaten on a $8.4 \mathrm{MJ} / \mathrm{d}$ diet. Weight-maintaining diets were provided based on estimated energy requirements. Diets were analysed using a program based on US Department of Agriculture data; additional values were obtained from foods analysed in the laboratory for protein, total fat and dietary fibre using AOAC methods (Association of Official Analytical Chemists, 1980) and fatty acids by GC (Jenkins et al. 2002). Additional dietary fibre values were obtained from the tables of Anderson \& Bridges (1988). Compliance was assessed from the completed weekly checklists and from the return of uneaten food items.

\section{Analyses}

Serum was analysed according to the Lipid Research Clinics protocols (US Department of Health \& Human Services, 1982) for total Chol, TG and HDL-Chol levels, after dextran sulfate- $\mathrm{MgCl}_{2}$ precipitation (Warnick et al. 1982). All samples from a given individual were analysed in the same batch. LDL-Chol was calculated (Friedewald et al. 1972). Serum ApoB was measured by nephelometry (Fink et al. 1989). LDL electrophoretic characteristics were obtained by non-denaturing polyacrylamide gradient $(2-16 \%)$ gel electrophoresis from serum stored at $-70^{\circ} \mathrm{C}$ as described previously (St Pierre et al. 2001). Briefly, polyacrylamide gradient gel electrophoresis was performed using $80 \times 80 \mathrm{~mm}$ gels prepared in batches in our laboratory. A $15 \mathrm{~min}$ pre-run at $75 \mathrm{~V}$ preceded the electrophoresis of plasma samples at $150 \mathrm{~V}$ for $3 \mathrm{~h}$. Gels were stained for $1 \mathrm{~h}$ with Sudan black $(0.07 \%)$ and stored in acetic acid $(0.81 \% \mathrm{v} / \mathrm{v})-$ methanol $(4 \% \mathrm{v} / \mathrm{v})$ until analysis using the Imagemaster 1-D Prime computer software (Amersham Pharmacia Biotech, Baie d'Urfé, Qué., Canada). LDL size was extrapolated from the relative migration of four plasma standards of known diameter (Tchernof et al. 1996). The estimated diameter for the major peak in each scan was identified as the LDL-PPD. An integrated (or mean) LDL diameter was also computed (St Pierre et al. 2001). This integrated LDL particle size corresponded to the weighed mean size of all LDL subclasses in one individual. Analysis of pooled plasma standards revealed that measurements of LDL-PPD and LDL mean particle size were highly reproducible, with inter-assay $\mathrm{CV}<0.6 \%$. The relative proportion of LDL having a diameter $<25.5 \mathrm{~nm}(\mathrm{LDL} \%<25.5 \mathrm{~nm})$ was ascertained by computing the relative area of the densitometric scan $<25.5 \mathrm{~nm}$. The absolute concentration of Chol among particles with a diameter $<25.5 \mathrm{~nm}($ LDL-Chol $<25.5 \mathrm{~nm})$ was estimated by multiplying the total plasma LDL-Chol levels by the relative proportion of LDL with a diameter
$<25.5 \mathrm{~nm}$ as described previously (St Pierre et al. 2001). A similar approach was used to estimate the relative and absolute concentration of $\mathrm{Chol}$ in particles with a diameter $>26.0 \mathrm{~nm}(\mathrm{LDL} \%>260 \mathrm{~nm}$ and LDL-Chol $>260 \mathrm{~nm}$ respectively). The $\mathrm{CV}$ for the measurements of LDL $\%<25.5 \mathrm{~nm}$ and LDL \%>26.0 nm were 12.0 and $9.3 \%$ respectively.

\section{Statistical analysis}

Results are expressed as mean values with their standard deviations. Because no significant differences were found between weeks 2 and 4 (results not shown), their mean value was used as the combination diet value. The significance of the differences between the baseline period (week 0 ), the combination diet (mean of weeks $2+4$ ) and the run-out period (week 6 ) were assessed by the least square mean test with the Tukey multi-comparison adjustment using the PROC MIXED procedure. Values with a skewed distribution were log-normalised. There was no interaction between treatment and gender. Spearman rank correlation analysis was used to test for association between dietinduced changes in body weight and metabolic variables and changes in the various LDL electrophoretic characteristics. All analyses were conducted using the SAS software (version 8.2; SAS Institute Inc., Cary, NC, USA).

\section{Results}

As reported previously, compliance in terms of energy intake was good in most subjects, with a mean value of 92.5 (SD 2.9) \% of the prescribed energy consumed (Jenkins et al. 2002). The mean energy intake was greater on the combination diet compared with the baseline and run-out values. The combination diet was associated with a slight bodyweight reduction after 4 weeks compared with baseline values (mean $\Delta$ weight $_{\text {weeks }} 2+4$ v. $0-0.40$ (SD 0.80) kg), which was accentuated during the washout period (mean $\Delta$ weight $_{\text {week }} 6$ v.0 -1.20 (SD 0.90$) \mathrm{kg}$ ). Subjects lost body weight at an average rate of -0.10 (SD 0.05$) \mathrm{kg}$ per week on the experimental combination diet and -0.20 (SD 0.05) $\mathrm{kg}$ per week during the run-out phase.

\section{Blood lipids}

Full details of the blood lipid responses have been reported previously (Jenkins et al. 2002). Significant reductions in blood lipids were seen during the experimental diet compared with the baseline (Table 2), including reductions from baseline in LDL-Chol levels (30.0 (SE 3.0)\%, $P<0.0001)$ and the total Chol:HDL-Chol ratio $(18.6$ (SE $3 \cdot 1) \%, P<0 \cdot 0001$, results not shown).

\section{LDL size phenotype}

As shown in Table 2, the combination diet had no significant effect on LDL-PPD. On the other hand, the LDL integrated size, which reflects the whole distribution of LDL based on all subclasses in a given individual, was significantly reduced $(P<0.01)$ following the combination diet, suggesting a shift in the distribution of LDL from larger to smaller species. This was confirmed by densitometric 
Table 2. Fasting serum lipid and lipoprotein levels and LDL particle electrophoreric characteristics*

(Mean values with their standard deviations for twelve subjects)

\begin{tabular}{|c|c|c|c|c|c|c|c|c|}
\hline \multirow[b]{2}{*}{ Variable } & \multicolumn{2}{|c|}{$\begin{array}{l}\text { Baseline } \\
\text { (week 0) }\end{array}$} & \multicolumn{2}{|c|}{$\begin{array}{l}\text { Mean treatment } \\
\text { (weeks } 2-4)\end{array}$} & \multicolumn{2}{|c|}{$\begin{array}{l}\text { Run-out } \\
\text { (week 6) }\end{array}$} & \multicolumn{2}{|c|}{ Statistical significance of effect: $P$} \\
\hline & Mean & SD & Mean & SD & Mean & SD & Treatment $v$. baseline & Run-out $v$. baseline \\
\hline Weight (kg) & $70 \cdot 0$ & $13 \cdot 7$ & 69.5 & $13 \cdot 1$ & $68 \cdot 7$ & $13 \cdot 0$ & 0.02 & $<0.0001$ \\
\hline Total cholesterol $(\mathrm{mmol} / \mathrm{l}) \dagger$ & 6.37 & 0.80 & 4.97 & 0.76 & 5.95 & 0.82 & $<0.0001$ & $<0.05$ \\
\hline LDL-cholesterol $(\mathrm{mmol} / \mathrm{l})$ & $4 \cdot 20$ & 0.42 & 2.95 & 0.63 & $3 \cdot 82$ & 0.76 & $<0.0001$ & 0.04 \\
\hline HDL-cholesterol $(\mathrm{mmol} / \mathrm{l})$ & 1.38 & 0.41 & 1.33 & 0.43 & 1.34 & 0.44 & 0.44 & 0.55 \\
\hline Triacylglycerol $(\mathrm{mmol} / \mathrm{l}) \neq$ & 1.87 & 1.31 & 1.52 & 0.76 & 1.72 & 1.01 & 0.04 & 0.34 \\
\hline Apo B (g/l) & $1 \cdot 31$ & $0 \cdot 17$ & 1.00 & 0.19 & $1 \cdot 26$ & 0.20 & $<0.0001$ & 0.25 \\
\hline \multicolumn{9}{|l|}{ LDL particle size phenotype } \\
\hline LDL-peak particle diameter $(\AA)$ & 255.4 & $5 \cdot 3$ & 255.4 & 4.3 & $256 \cdot 3$ & 4.7 & 0.98 & 0.33 \\
\hline LDL-integrated size $(\AA)$ & $257 \cdot 0$ & 4.0 & 255.7 & 2.9 & $256 \cdot 0$ & 3.9 & $<0.01$ & 0.18 \\
\hline $\mathrm{LDL}_{>26.0(\%) \S}$ & 37.8 & 13.4 & 33.9 & 8.0 & 38.2 & $10 \cdot 0$ & $<0.05$ & 0.85 \\
\hline $\mathrm{LDL}_{25.5-26.0(\%) \S}$ & $19 \cdot 1$ & $3 \cdot 1$ & $19 \cdot 6$ & $3 \cdot 8$ & $20 \cdot 4$ & $5 \cdot 1$ & 0.35 & 0.35 \\
\hline $\mathrm{LDL}<25.5 \% \S$ & $43 \cdot 1$ & $15 \cdot 8$ & $46 \cdot 5$ & $11 \cdot 3$ & 41.5 & $14 \cdot 1$ & 0.05 & 0.63 \\
\hline LDL-Chol $26.0(\mathrm{mmol} / \mathrm{l})$ & 1.55 & 0.49 & 0.99 & 0.24 & 1.45 & 0.45 & $<0.0001$ & 0.43 \\
\hline LDL-Chol $25.5-26.0(\mathrm{mmol} / \mathrm{l})$ & 0.80 & 0.13 & 0.57 & 0.14 & 0.78 & 0.27 & $<0.0001$ & 0.81 \\
\hline LDL-Chol ${ }_{25.5}(\mathrm{mmol} / \mathrm{l})$ & 1.85 & 0.82 & 1.39 & 0.56 & 1.59 & 0.68 & $<0.01$ & $<0.05$ \\
\hline
\end{tabular}

${ }^{*}$ For details of diets, subjects and procedures, see pp. 658-659.

t $n 11$.

$\ddagger$ Values were log-transformed before statistical analyses.

$\S$ Relative proportion of LDL with diameters $<26 \cdot 0,22.5-26.0$ or $<25.5 \mathrm{~nm}$ respectively.

analysis of the relative proportion of small and large LDL particles. The combination diet was associated with a reduction in $\mathrm{LDL} \%>260 \mathrm{~nm}$ (from 37.8 to $33.9 \%$, $P<0.05)$ and with a diametrical increase in LDL $\%<25.5 \mathrm{~nm}$ (from 43.1 to $46.5 \%, P=0.05$ ). Both LDL $\%<25.5 \mathrm{~nm}$ and LDL $\%>260 \mathrm{~nm}$ came back to baseline values during the run-out phase of the study.

By comparison with baseline levels, the experimental diet reduced the absolute concentrations of all three distinct LDL subclasses, including LDL-Chol $<25.5 \mathrm{~nm}$ (Table 2). Thus, the reduction in $\mathrm{LDL}_{-\mathrm{Chol}_{>260 \mathrm{~nm}} \text {, LDL-Chol }} 55-5-26.0 \mathrm{~nm}$ and $\mathrm{LDL}_{-C h o l}<25.5 \mathrm{~nm}$ averaged $\quad-0.57 \quad(\mathrm{SD} \quad 0.37) \mathrm{mmol} / \mathrm{l}$ $(P<0.0001),-0.23 \quad($ SD 0.09$) \mathrm{mmol} / \mathrm{l} \quad(P<0.0001)$ and $-0.45 \quad$ (SD 0.51$) \mathrm{mmol} / \mathrm{l} \quad(P<0.01)$ respectively (total LDL-Chol reduction $1.25 \mathrm{mmol} / \mathrm{l}, P<0.0001)$. There was no correlation between diet-induced changes in body weight and changes in any of the LDL electrophoretic characteristics measured in the present study. However, multivariate adjustment for diet-induced variation in body weight attenuated to some extent the impact of the combination diet on LDL\% $<25.5 \mathrm{~nm}$ and LDL\% $>260 \mathrm{~nm}(P=0.07$ and $P=0.08$ respectively). Diet-induced changes in plasma TG levels were associated with simultaneous changes in LDL-PPD $(r-0.52, P=0.08)$, but not with changes in the relative proportion of small $(r 0 \cdot 38, P=0 \cdot 22)$ or large LDL $(r-0 \cdot 46, P=0 \cdot 13)$.

Subgroup analysis based on the median distribution of LDL-Chol $_{<25.5 \mathrm{~nm}}$ at baseline $(1.72 \mathrm{mmol} / \mathrm{l})$ indicated that the group with $\mathrm{LDL}-\mathrm{Chol}_{<25.5 \mathrm{~nm}}>1.72 \mathrm{mmol} / \mathrm{l}$ at baseline (n 6) comprising a greater proportion of men, had higher plasma LDL-Chol $(+0.54 \mathrm{mmol} / \mathrm{l})$ and ApoB $(+0.23 \mathrm{~g} / \mathrm{l})$ levels and smaller LDL-PPD $(-7.4 \AA)$ compared with subjects with LDL-Chol $<25.5 \mathrm{~nm}<1.72 \mathrm{mmol} / 1$ at baseline $(n$ $6)$; they also tended to have higher TG levels $(+1.27 \mathrm{mmol} / \mathrm{l})$ and lower HDL-Chol levels $(-0.35 \mathrm{mmol} /$ 1). Baseline LDL-Chol $<25.5 \mathrm{~nm}$ levels appeared to be a significant determinant of the experimental diet effect on LDL size phenotype. As shown in Fig. 1, subjects with increased LDL$\mathrm{Chol}_{<25.5 \mathrm{~nm}}$ levels at baseline experienced a significant reduction $(P<0.001)$ in $\mathrm{LDL}-\mathrm{Chol}_{<25.5 \mathrm{~nm}}$ concentrations and showed an increase in LDL-PPD following the experimental diet. Total plasma LDL-Chol levels were also reduced significantly in this group of subjects $(-31.4 \%$, $P<0.01)$. The further increase in LDL-PPD during the washout phase in subjects with LDL-Chol $_{<25.5 \mathrm{~nm}}$ levels $>1.72 \mathrm{mmol} / \mathrm{l}$ may be explained by the fact that these subjects showed a greater decrease in body weight (run-out $v$. baseline) compared with those with LDL-Chol $_{<25.5 \mathrm{~nm}}$ $<1.72 \mathrm{mmol} / \mathrm{l}$ at baseline $(1.53 v .0 .96 \mathrm{~kg}$ respectively, results not shown). On the other hand, in subjects with relatively lower $\mathrm{LDL}-\mathrm{Chol}_{<25.5 \mathrm{~nm}}$ levels at baseline, the diet had virtually no impact on LDL-Chol $<25.5 \mathrm{~nm}$ levels and LDL-PPD was reduced by $0 \cdot 3 \mathrm{~nm}$. However, the magnitude of the diet-induced reduction in total plasma LDL-Chol levels $(-28.6 \%, P<0.0001)$ was not attenuated in this subgroup of subjects compared with individuals with high levels of LDL-Chol $<25.5 \mathrm{~nm}$ at baseline.

\section{Discussion}

The results from the present study have been reported previously, showing that a diet incorporating soyabean protein, phytosterols, viscous fibre and almonds to the diet of hypercholesterolaemic subjects produced some of the largest reductions in LDL-Chol reported for largely weightmaintaining dietary interventions (Jenkins et al. 2002, 2003). The question therefore arose as to whether the total LDL-Chol reduction was also reflected in a corresponding reduction in the levels of the most atherogenic LDL particles (LDL with diameter $<25.5 \mathrm{~nm}$ ) (St Pierre et al. 2001).

Despite a reduction in the proportion of larger LDL particles on the combination diet leading to a relative increase in the proportion of small LDL particles and a 


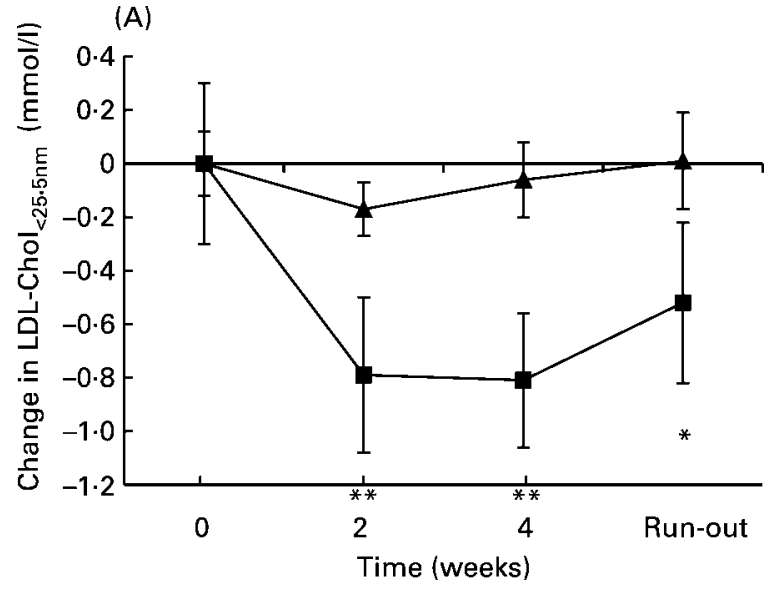

(B)

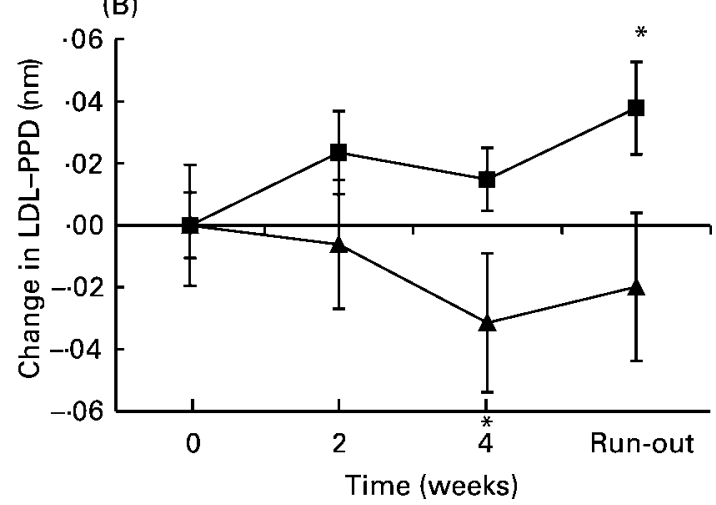

Fig. 1. Impact of the combination diet on the relative proportion of LDL-cholesterol (chol) with a diameter $<25.5 \mathrm{~nm}$ (LDL$\mathrm{Chol}_{<25.5 \mathrm{~nm}}$ ) levels (A) and LDL peak particle diameter (PPD, (B)) in subjects with high or low levels of LDL-Chol $<25.5 \mathrm{~nm}$ at baseline. $\boldsymbol{\Delta}$, Baseline LDL-Chol $<25.5 \mathrm{~nm}<1.72 \mathrm{mmol} /$; $\mathbf{\square}$, baseline LDL$\mathrm{Chol}_{<25.5 \mathrm{~nm}}>1.72 \mathrm{mmol} / \mathrm{l}$. Values are means with their standard errors shown by vertical bars for twelve subjects. For details of subjects, diets and procedures, see pp. 658-659. LDL-Chol $<25.5 \mathrm{~nm}$ corresponds to the Chol levels in the small LDL subfraction, i.e. $\mathrm{LDL}$ with a diameter $<25.5 \mathrm{~nm}$ and $1.72 \mathrm{mmol} / \mathrm{l}$ is the median value at baseline among the study participants. There were a significant group $\times$ treatment interactions: $(\mathrm{A}), P=0.02$; $(\mathrm{B}), P=0.002$. Mean values were significantly different from those at baseline: ${ }^{*} P<0.05$, ${ }^{* *} P<0.001$.

corresponding decrease in LDL integrated size, plasma Chol levels in the small LDL subfraction (LDL$\left.\mathrm{Chol}_{<25.5 \mathrm{~nm}}\right)$ were reduced significantly $(P<0.01)$. The magnitude of the reduction in $\mathrm{LDL}-\mathrm{Chol}_{<25.5 \mathrm{~nm}}$ levels of $0.45 \mathrm{mmol} / \mathrm{l}$ seen with the experimental diet is almost equivalent to the difference of $0.6 \mathrm{mmol} / \mathrm{l}$ in LDL-Chol $_{<25.5 \mathrm{~nm}}$ levels between men who remained free from heart disease (1.5 (SD 0.9) mmol/l) compared with those who developed IHD $(2 \cdot 1$ (SD 0.8$) \mathrm{mmol} / \mathrm{l})$ over the 5-year follow-up in the Québec Cardiovascular Study (St Pierre et al. 2001). This mean reduction in LDL-Chol $<25.5 \mathrm{~nm}$ levels attributable solely to the combination diet would translate into a $30 \%$ reduction in the 5-year risk of IHD based on the Québec Cardiovascular Study results. These results from more than 2000 men followed for 5 years demonstrated that LDL$\mathrm{Chol}_{<25.5 \mathrm{~nm}}$ levels were a much more potent risk factor for IHD than the more traditionally used LDLPPD (St Pierre et al. 2001).
A small weight loss occurred on the combination diet when energy intake was greater than when subjects were consuming their usual therapeutic diets ad libitum. We believe this discrepancy may be largely explained by the tendency to under-reporting often seen in dietary records of self-selected diets, which has been shown to account for as much as $20 \%$ total energy intake (Sawaya et al. 1996). It has been reported previously that body weight changes induced by exercise or diet were important determinants of concurrent changes in LDL-PPD (Williams et al. 1990) and that individuals with a predominance of small LDL experienced a greater responsiveness to dietary changes (Krauss \& Dreon, 1995) and weight loss (Purnell et al. 2000).

In our previous analyses, we have shown that baseline total LDL-Chol concentrations or diet-induced variation in body weight did not appear to influence the lipoprotein-lipid response to the combination diet (Jenkins et al. 2002). Perhaps the most interesting finding of the present study is the fact that high-risk individuals (risk based on the LDL size phenotype at baseline) had a more favourable response to the combination diet compared with low-risk individuals. Our present results may be explained by the fact that subjects with LDL-Chol $<25.5 \mathrm{~nm}$ levels $>1.72 \mathrm{mmol} / \mathrm{l}$ at baseline also had smaller LDL-PPD at baseline and lost more weight compared with subjects with $\mathrm{LDL}^{-C h o l}<25.5 \mathrm{~nm}$ levels $<1.72 \mathrm{mmol} / \mathrm{l}$. Although the cut-off point that we used to define low- $v$. high-risk individuals was arbitrarily defined as the median LDL$\mathrm{Chol}_{<25.5 \mathrm{~nm}}$ levels in our present twelve subjects, results from the Québec Cardiovascular Study indicate that men with $\mathrm{LDL}^{-C h o l}<25.5 \mathrm{~nm}$ levels $>1.72 \mathrm{mmol} / \mathrm{l}$ had a $60 \%$ greater risk of IHD compared with those with $\mathrm{LDL}_{-C h o l}<25.5 \mathrm{~nm}$ levels $<1.72 \mathrm{mmol} / 1$ (B Lamarche, AC St Pierre, B Cantin, GR Dagenais and JP Després, unpublished results). In subjects with low levels of LDL$\mathrm{Chol}_{<25.5 \mathrm{~nm}}$ at baseline, the impact of the combination diet on LDL particle size phenotype was marginal. LDLPPD decreased by $3 \AA$, but the on-diet value $(25.6 \mathrm{~nm})$ did not go below the cut-off point that we have identified as being the critical value below which the risk of CVD significantly increases in men $(25.6 \mathrm{~nm}$; Lamarche et al. 2001). In addition, plasma levels of $\mathrm{LDL}_{-C h o l}<25.5 \mathrm{~nm}$ were not altered (positively or negatively) by the experimental diet in patients with low levels of LDL$\mathrm{Chol}_{<25.5 \mathrm{~nm}}$ at baseline. While we fully recognise that these sub-analyses are based on small numbers of subjects with the need to reproduce them in larger cohorts of patients, our present results suggest that the combination diet may be of tremendous value clinically in high-risk patients presenting with one of the typical features of the metabolic syndrome, i.e. small dense LDL particles. The extent to which variations in body weight contributed to alterations in the LDL size phenotype associated with the combination diet will also have to be addressed in future studies.

There is currently limited data on the individual effects of viscous fibre, soyabean protein, phytosterols and almonds on the characteristics of the LDL particle size phenotype. Although perhaps counterintuitive, low-saturated fat diets have been shown to reduce LDL-PPD (Krauss \& 
Dreon, 1995; Dreon et al. 1997, 1998). To our knowledge, three studies have investigated the effect of soyabean protein on LDL particle size. The first two of these studies were conducted in free-living normolipidaemic premenopausal and in normolipidaemic or mildly hypercholesterolaemic postmenopausal women. These subjects consumed their usual diet, which was supplemented with one of the three isolated-soyabean-protein beverage powders, accounting for slightly less than one-half of the daily protein intake (Merz-Demlow et al. 2000; Wangen et al. 2001). Neither study reported a significant change in LDL-PPD as a result of incorporating isolated-soyabeanprotein beverage powders into the diet. On the other hand, we have recently shown in a study conducted under strictly controlled conditions that the daily consumption of $>50 \mathrm{~g}$ soyabean protein, with or without isoflavones, increased LDL-PPD and induced a favourable redistribution of Chol from small to large LDL subclasses when compared with an animal-protein based diet (Desroches et al. 2004).

The impact of almonds or other nuts on LDL size is unclear. A study conducted in free-living patients showed that incorporating walnuts in the subjects' habitual diets (approximately $24 \mathrm{~g} / 4 \cdot 2 \mathrm{MJ}$ ) induced a significant reduction in the Chol content of small LDL sub-fractions, while LDL-PPD and LDL-Chol remained unchanged compared with the subjects' habitual diets (Almario et al. 2001). It must be stressed that incorporation of walnuts in the diet also led to a non-significant but important increase in the mean energy intake from fat ( 31.4 to $37.2 \%$ ), as well as with a significant change in the composition of dietary fat. However, substituting saturated fat with PUFA or MUFA does not seem to alter LDL size (Dreon et al. 1990; Kratz et al. 2002; Rivellese et al. 2003).

To the best of our knowledge, only two studies have investigated the impact of dietary phytosterols on LDL particle size phenotype. In the first study, it was shown that the daily consumption of $2.7 \mathrm{~g}$ phytosterol-supplemented ground beef had no significant impact on LDL-PPD; no other measures of LDL particle size phenotype were investigated (Matvienko et al. 2002). In a more recent study, we have shown that in moderately hypercholesterolaemic subjects, consumption of unesterified stanols, sterols, or both as butter, did not induce significant changes in LDL-PPD (Charest et al. 2004). The phytosterol-induced reduction in LDL-Chol levels were attributable only to a reduction in the Chol content of large LDL particles $(>26.0 \mathrm{~nm})$, with no change in the Chol levels of small particles $(<25.5 \mathrm{~nm}$; Charest et al. 2004).

Finally, one study has compared the impact of incorporating two servings ( $14 \mathrm{~g}$ dietary fibre/d) of oat cereal or wheat cereal on LDL size (Davy et al. 2002). The results indicated that LDL particle size was comparable after consumption of the two cereals, but that Chol within small LDL particles was reduced with oat cereal, whereas it was increased with the wheat cereal.

Taken together, results from the studies described earlier suggest that the individual nutritional components of our present combination diet have either no effect or beneficial effects on LDL particle phenotype. We hypothesise that the soyabean protein, almonds and viscous fibre may be responsible for the reduction in the Chol content of the small LDL particles, whereas the phytosterol component of the combination diet may have been responsible for the reduction in the Chol content within large LDL particles. It cannot be firmly excluded that part of the dietinduced changes in LDL size phenotype may be attributed to other differences between the baseline and the experimental diet, such as levels of dietary Chol and of saturated fatty acids and PUFA.

We conclude that a dietary combination of foods that have been shown to induce marked reduction in plasma LDL-Chol levels may also favourably alter important aspects of the LDL particle size phenotype, including LDL-Chol $<25.5 \mathrm{~nm}$ levels, particularly in subjects with a suboptimal phenotype at baseline. These results need to be replicated in larger samples of subjects and for a longer time period in order to address effectiveness of the diet over the longer-term, when availability of foods and compliance are major issues. Nevertheless, the magnitude of the reduction in plasma LDL-Chol levels, which essentially matched that achieved using pharmacological therapy (Jenkins et al. 2003), combined with the favourable changes in small dense LDL-Chol levels (LDL-Chol $<25.5 \mathrm{~nm}$ ), identify this diet as a potentially potent dietary strategy to reduce the risk of CVD in high-risk individuals.

\section{Acknowledgements}

The authors sincerely thank Loblaw Brands Ltd (Toronto, Ont., Canada), Unilever Canada (Toronto, Ont., Canada), the Almond Board of California (Modesto, CA, USA) and Procter and Gamble Canada (Toronto, Ont., Canada) for the generous donation of foods used in the present study. The authors wish to thank Mr Robert Chenaux and Mr Larry C. Griffin of Loblaw Brands Ltd, Mr Paul Shur of Unilever Canada, Ms Kathy Galbraith of Natural Temptations Bakery, Burlington, Ont., Canada, for their assistance on this project. This research was partly supported by the Canada Research Chair in Nutrition, Functional Foods and Cardiovascular Health (B. L.) and Nutrition and Metabolism (D. J. A. J.).

\section{References}

Almario RU, Vonghavaravat V, Wong R \& Kasim-Karakas SE (2001) Effects of walnut consumption on plasma fatty acids and lipoproteins in combined hyperlipidemia. Am J Clin Nutr 74, 72-79.

Anderson JW \& Bridges SR (1988) Dietary fiber content of selected foods. Am J Clin Nutr 47, 440-447.

Association of Official Analytical Chemists (1980) AOAC Official Methods of Analysis. Washington, DC: AOAC

Charest A, Vanstone CA, Desroches S, Jones PJ \& Lamarche B (2004) Unesterified plant sterols and stanols do not affect LDL electrophoretic characteristics in hypercholesterolemic subjects. J Nutr 134, 592-595.

Davy BM, Davy KP, Ho RC, Beske SD, Davrath LR \& Melby CL (2002) High-fiber oat cereal compared with wheat cereal consumption favorably alters LDL-cholesterol subclass and particle numbers in middle-aged and older men. Am J Clin Nutr 76, 351-358.

Desroches S, Mauger J-F, Ausman LM, Lichtenstein AH \& 
Lamarche B (2004) Soy protein favorably affects LDL size independently of isoflavones in hypercholesterolemic men and women. $J$ Nutr 134, 574-579.

Dreon DM, Fernstrom HA, Campos H, Blanche P, Williams PT \& Krauss RM (1998) Change in dietary saturated fat intake is correlated with change in mass of large low-density-lipoprotein particles in men. Am J Clin Nutr 67, 828-836.

Dreon DM, Fernstrom HA, Williams PT \& Krauss RM (1997) LDL subclass patterns and lipoprotein response to a low-fat, high-carbohydrate diet in women. Arterioscler Thromb Vasc Biol 17, 707-714.

Dreon DM, Vranizan KM, Krauss RM, Austin MA \& Wood PD (1990) The effects of polyunsaturated fat vs monounsaturated fat on plasma lipoproteins. J Am Med Assoc 263, 2462-2466.

Fink PC, Romer M, Haeckel R, Fateh-Moghadam A, Delange J, Gressner AM \& Dubs RW (1989) Measurement of proteins with the Behring nephelometer. A multicentre evaluation. J Clin Chem Clin Biochem 27, 261-276.

Friedewald WT, Levy RI \& Fredrickson DS (1972) Estimation of the concentration of low-density lipoprotein cholesterol in plasma, without use of the preparative ultracentrifuge. Clin Chem 18, 499-502.

Gardner CD, Fortmann SP \& Krauss RM (1996) Association of small low-density lipoprotein particles with the incidence of coronary artery disease in men and women. $\mathrm{J} \mathrm{Am} \mathrm{Med} \mathrm{Assoc}$ 276, 875-881.

Jenkins DJ, Kendall CW, Faulkner D, et al. (2002) A dietary portfolio approach to cholesterol reduction: combined effects of plant sterols, vegetable proteins, and viscous fibers in hypercholesterolemia. Metabolism 51, 1596-1604.

Jenkins DJ, Kendall CW, Marchie A, et al. (2003) Effects of a dietary portfolio of cholesterol-lowering foods vs lovastatin on serum lipids and C-reactive protein. J Am Med Assoc 290, 502-510.

Jenkins DJ, Kendall CW, Popovich DG, et al. (2001) Effect of a very-high-fiber vegetable, fruit, and nut diet on serum lipids and colonic function. Metabolism 50, 494-503.

Kratz M, Gülbahçe E, von Eckardstein A, Cullen P, Cignarella A, Assmann G \& Wahrburg U (2002) Dietary mono- and polyunsaturated fatty acids similarly affect LDL size in healthy men and women. $J$ Nutr 132, 715-718.

Krauss RM \& Dreon DM (1995) Low-density-lipoprotein subclasses and response to a low-fat diet in healthy men. $\mathrm{Am}$ $J$ Clin Nutr 62, 478S-487S.

Lamarche B, Lemieux I \& Despres JP (1999) The small, dense LDL phenotype and the risk of coronary heart disease: epidemiology, patho-physiology and therapeutic aspects. Diabetes Metab 25, 199-211.

Lamarche B, St Pierre AC, Ruel IL, Catin B, Dagenais GR \& Despres JP (2001) A prospective, population-based study of low density lipoprotein particle size as a risk factor for ischemic heart disease in men. Can J Cardiol 17, 859-865.

Lamarche B, Tchernof A, Moorjani S, Cantin B, Dagenais GR, Lupien PJ \& Despres JP (1997) Small, dense low-density lipoprotein particles as a predictor of the risk of ischemic heart disease in men. Prospective results from the Québec cardiovascular study. Circulation 95, 69-75.

Matvienko OA, Lewis DS, Swanson M, Arndt B, Rainwater DL, Stewart J \& Alekel DL (2002) A single daily dose of soybean phytosterols in ground beef decreases serum total cholesterol and LDL cholesterol in young, mildly hypercholesterolemic men. Am J Clin Nutr 76, 57-64.

Merz-Demlow BE, Duncan AM, Wangen KE, Xu, Carr TP, Phipps WR \& Kruzer MS (2000) Soy isoflavones improve plasma lipids in normocholesterolemic, premenopausal women. Am J Clin Nutr 71, 1462-1469.

National Cholesterol Education Program (2002) Third Report of the National Cholesterol Education Program (NCEP) Expert Panel on Detection, Evaluation, and Treatment of High Blood Cholesterol in Adults (Adult Treatment Panel III). Final Report. Circulation 106, 3143-3421.

Purnell JQ, Kahn SE, Albers JJ, Nevin DN, Burnzell JD \& Schwartz RS (2000) Effect of weight loss with reduction of intra-abdominal fat on lipid metabolism in older men. J Clin Endocrinol Metab 85, 977-982.

Rivellese AA, Maffettone A, Vessby B, Uusitupa M, Hermansen K, Berglund L, Louheranta A, Meyer BJ \& Riccardi G (2003) Effects of dietary saturated, monounsaturated and n-3 fatty acids on fasting lipoproteins, LDL size and post-prandial lipid metabolism in healthy subjects. Atherosclerosis 167, $149-158$.

Sawaya AL, Tucker K, Tsay R, Willett W, Saltzman E, Dallal GE \& Roberts SB (1996) Evaluation of four methods for determining energy intake in young and older women: comparison with doubly labeled water measurements of total energy expenditure. Am J Clin Nutr 63, 491-499.

St Pierre AC, Ruel IL, Cantin B, Dagenais GR, Bernard PM, Despres JP \& Lamarche B (2001) Comparison of various electrophoretic characteristics of LDL particles and their relationship to the risk of ischemic heart disease. Circulation 104, 2295-2299.

Tchernof A, Lamarche B, Prud'homme D, Nedeau A, Moorjani S, Labrie F, Lupien PJ \& Despres JP (1996) The dense LDL phenotype. Association with plasma lipoprotein levels, visceral obesity, and hyperinsulinemia in men. Diabetes Care 19, 629-637.

US Department of Agriculture (2003) Health Claims that Meet Significant Scientific Agreement (SSA). http://www cfsan fda gov/ dms/lab-ssa html

US Department of Health and Human Services (1982) Lipid Research Clinic: Manual of Laboratory Operations. Lipid and Lipoprotein Analyses. National Institutes of Health Publication no. 75-778, revised edition. Washington DC: US Government Printing Office.

Wangen KE, Duncan AM, Xu X \& Kurzer MS (2001) Soy isoflavones improve plasma lipids in normocholesterolemic and mildly hypercholesterolemic postmenopausal women. Am J Clin Nutr 73, 225-231.

Warnick GR, Benderson J \& Albers JJ (1982) Dextran sulfate$\mathrm{Mg}^{2+}$ precipitation procedure for quantitation of high-density-lipoprotein cholesterol. Clin Chem 28, 1379-1388.

Williams PT, Krauss RM, Vranizan KM \& Wood PD (1990) Changes in lipoprotein subfractions during diet-induced and exercise-induced weight loss in moderately overweight men. Circulation 81, 1293-1304.

Wolever TM, Hegele RA, Connelly PW, Ransom TP, Story JA, Furumoto EJ \& Jenkins DJ (1997) Long-term effect of soluble-fiber foods on postprandial fat metabolism in dyslipidemic subjects with apo E3 and apo E4 genotypes. Am J Clin Nutr 66, 584-590. 